Gut, 1982, 23, 517-523

\title{
Patterns of small intestinal motility in duodenal ulcer patients before and after vagotomy*
}

\author{
D G THOMPSON, H D RITCHIE, and D L WINGATE $\dagger$ \\ From the Departments of Medicine, Gastrointestinal Science, and Surgery, London Hospital Medical \\ College, London
}

SUMMARY Prolonged (18-24 hours) recordings of the pattern of small intestinal motor activity have been made, using radiotelemetry, in seven patients before surgery for chronic duodenal ulcer, seven after truncal vagotomy, and four with persistent post-vagotomy diarrhoea. There was no difference in the pattern of fasting cyclical activity between the three groups but the duration of feeding activity after a standard meal was reduced in asymptomatic truncal vagotomy patients compared with duodenal ulcer controls $(\mathrm{p}<0.05)$. In patients with post-vagotomy diarrhoea, the duration of the feeding pattern was further reduced compared with the asymptomatic post-vagotomy patients $(\mathrm{p}<0.01)$. It is suggested that altered emptying of food from the stomach in these patients together with duodenal receptor insensitivity is the probable explanation of these changes.

Periodic changes in fasting upper gastrointestinal motility have been recognised since the work of Boldyreff $^{1}$ both in dogs and in man. Phases of activity alternate with quiescence (phase I), the activity being further divisible into an irregular period (phase II) followed by a brief, but characteristic, phase of regular activity (phase III, activity front) with a frequency in the human upper small intestine of approximately $11 / \mathrm{min}$. The motor activity migrates slowly from the lower oesophageal sphincter ${ }^{2}$ to the terminal ileum.

Studies of the phenomenon in man have been hampered by lack of suitable techniques, the standard method using a perfused tube system is cumbersome and restricting. We have recently shown ${ }^{3}$ that the use of a miniature ingested radiotelemetry capsule tethered at the duodenojejunal flexure can provide data at that site equivalent to that obtained with perfused catheter (Fig. 1) but with the major advantages of comfort and mobility, allowing prolonged study with normal food intake. This method has demonstrated a wide variation in the normal pattern with diurnal changes in cycle length and character. ${ }^{3}$

\footnotetext{
* Preliminary accounts of these findings were given to the American Gastroenterology Association in May 1980 and to the British Society of Gastroenterology in September 1980.

$\dagger$ Address for correspondence: Dr D L Wingate, London Hospital, Whitechapel, London E1 1BB, England.

Received for publication 19 October 1981
}

Ingestion of a meal results in disruption of fasting activity for a variable period before the fasting pattern, identified by the reappearance of regular contractile activity (phase III), resumes. ${ }^{3}$

The neurohumoral mechanisms controlling this activity remain elusive. It has been suggested that the vagus exerts some control ${ }^{4}$ as shown by decreased regularity of cyclical activity in dogs after truncal (thoracic) vagotomy. Others, ${ }^{56}$ however, have failed to find such a change. Fewer observations have been reported in man after vagotomy. Glazebrook $^{7}$ recognised 'spasms' of the small intestine (probable phase III activity) in patients after vagotomy but did not provide data on the incidence of 'spasms' in healthy subjects. Roth and Beams $^{8}$ also stated that the number of intestinal 'spasms' was greater after vagotomy but again the periods of observation were brief and their definition of 'spasms' does not allow strict comparison with contemporary studies. Catchpole and Duthie, ${ }^{9}$ studying patients in the first four days after laparotomy, found no effect of vagotomy on fasting complexes, but their patients were not given a meal.

Studies on dogs in our laboratories by Reverdin et $a t^{6}$ had shown variable motor sequelae of vagotomy, but one common factor was a delay in gastric emptying combined with a diminished or absent motor response to feeding with, as a result, the resumption of migrating complexes before the 

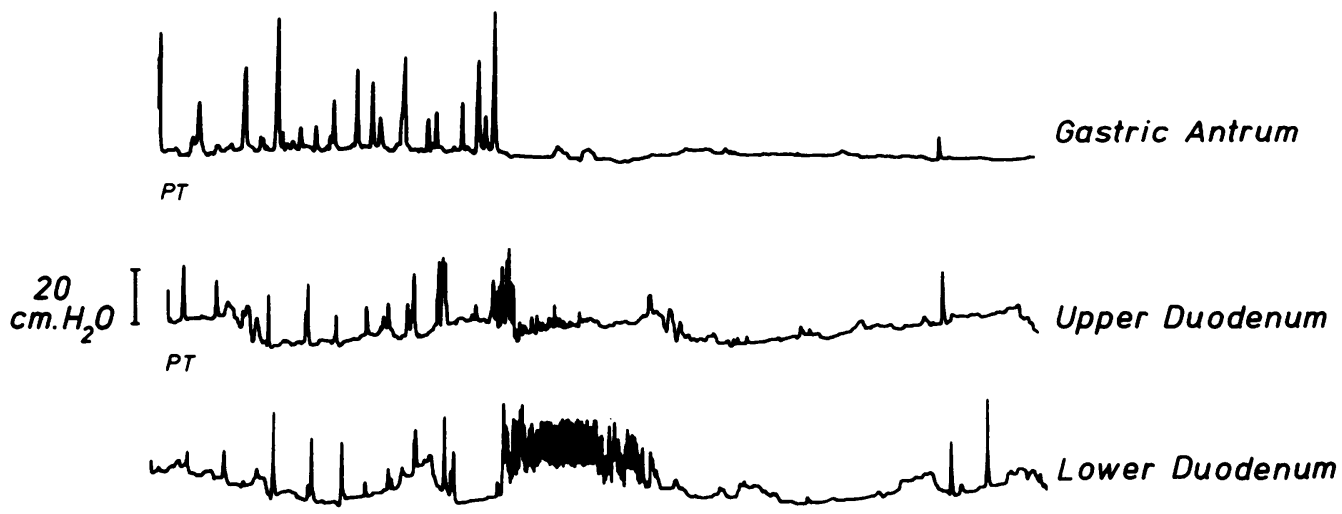

PT



Fig. 1 Recording of a human fasting migrating complex by four sensors spaced at $10 \mathrm{~cm}$ intervals in the proximal digestive tract. The upper three sensors were perfused tubes (PT) with attached transducers, and the distal sensor $(R P)$ was a radio-pill. Inspection of the bottom line alone shows the easily-identifiable appearance of a migrating complex passing the radio-pill.

completion of gastric emptying (as shown by radiological examination). This raised the speculation that this disturbance might be an aetiological factor in post-vagotomy diarrhoea through the rapid propulsion of maldigested nutrients, and bile acids ${ }^{9}$ into the colon. The appropriate model for study is clearly vagotomised man, both without and with post-vagotomy diarrhoea, with unoperated duodenal ulcer patients as controls.

\section{Methods}

\section{SUBJECTS}

Protocols for the study of jejunal motility using ingested probes or sensors were approved by the local ethical committee in February 1975, and for the study of ulcer patients using such methods in February 1979. All patients gave informed written consent to the study. Three groups of patients were studied.

The first group (mean age 42 years) comprised seven patients with chronic duodenal ulcer who were studied before undergoing elective surgery for their ulcer disease. In these patients, chronic ulcer disease had been radiologically confirmed in all cases, and endoscopically in most cases. All but one had undergone a standard pentagastrin test to measure their basal and stimulated acid secretion (Table 1).

The second group (Table 2) comprised seven patients (mean age 42 years) who had been submitted to truncal vagotomy 10-98 months before study, and who had a normal bowel habit.

The third group (Table 2) comprised four patients with persistent and troublesome diarrhoea since truncal vagotomy 15-63 months before study. In the latter group, routine clinical investigations had not revealed any other cause for diarrhoea, and the diarrhoea had proved refractory to conventional

Table 1 Details of chronic duodenal ulcer patients

\begin{tabular}{|c|c|c|c|c|c|c|}
\hline \multirow{2}{*}{\multicolumn{2}{|c|}{$\begin{array}{l}\text { Subject Age } \\
\text { no. } \quad(y r)\end{array}$}} & \multirow[b]{2}{*}{ Sex } & \multirow{2}{*}{$\begin{array}{l}\text { Duration } \\
\text { of } \\
\text { symptoms } \\
\text { (months) }\end{array}$} & \multicolumn{3}{|c|}{ Acid output ( $\mathrm{mmol} / \mathrm{h})$} \\
\hline & & & & Basal & Maximal $^{*}$ & Peak* \\
\hline 1 & 50 & $\mathbf{M}$ & 38 & - & - & - \\
\hline 2 & 56 & $\mathbf{F}$ & 72 & 7 & 34 & 41 \\
\hline 3 & 40 & $\mathbf{F}$ & 72 & 0.2 & 23 & 29 \\
\hline 4 & 40 & $\mathbf{F}$ & 64 & 6 & 25 & 32 \\
\hline 5 & 64 & $\mathbf{M}$ & 4 & 17 & 56 & 61 \\
\hline 6 & 25 & $\mathbf{M}$ & 35 & 8 & 57 & 70 \\
\hline 7 & 21 & $\mathbf{M}$ & 14 & 21 & 54 & 54 \\
\hline
\end{tabular}

* After pentagastrin $6 \mu \mathrm{g} / \mathrm{kg}^{-1}$ intramuscularly. 
Table 2 Details of truncal vagotomy patients

\begin{tabular}{|c|c|c|c|c|c|}
\hline \multicolumn{2}{|c|}{ Subject Age } & Sex & $\begin{array}{l}\text { Months } \\
\text { since } \\
\text { surgery }\end{array}$ & Operation & $\begin{array}{l}\text { Diar- } \\
\text { rhoea }\end{array}$ \\
\hline 1 & 38 & $\mathbf{F}$ & 26 & TV + gastroenterostomy & - \\
\hline 2 & 38 & $\mathbf{M}$ & 10 & TV+pyloroplasty & - \\
\hline 3 & 43 & $\mathbf{M}$ & 24 & TV+pyloroplasty & - \\
\hline 4 & 51 & $\mathbf{F}$ & 10 & TV+pyloroplasty & - \\
\hline 5 & 34 & $\mathbf{M}$ & 27 & $\mathrm{TV}+$ gastroenterostomy & - \\
\hline 6 & 47 & $\mathbf{M}$ & 98 & TV + pyloroplasty & - \\
\hline 7 & 37 & $\mathbf{M}$ & 76 & TV + pyloroplasty & - \\
\hline 8 & 48 & $\mathbf{M}$ & 15 & $\mathrm{TV}+$ pyloroplasty & + \\
\hline 9 & 61 & $\mathbf{M}$ & 62 & TV + pyloroplasty & + \\
\hline 10 & 68 & $\mathbf{F}$ & 63 & $T V+$ roux-en-Y & + \\
\hline 11 & 49 & $\mathbf{M}$ & 25 & TV + pyloroplasty & + \\
\hline
\end{tabular}

therapy with such agents as codeine phosphate, diphenoxylate, and loperamide.

A preponderance of males in the operated group (Table 2) reflected current British trends in ulcer surgery. All operated subjects showed evidence of adequate vagotomy as manifested by complete and lasting relief of symptoms, or negative Hollander test, or both. Preoperative and postoperative clinical investigations were not uniform in all subjects as these were instituted on clinical grounds by several medical and surgical services with differing management strategies for ulcer surgery; the study protocol defined only the criteria for inclusion and the conduct of the motility studies.
PROCEDURE

All studies were performed using an ingested radiotelemetry capsule and recording apparatus as previously described. ${ }^{3}$ On the morning after an overnight fast, subjects, who had given informed consent, swallowed the transducer capsule which was allowed to pass to the duodenojejunal flexure or into the efferent loop of a gastroenterostomy before the attached thread was tethered to the cheek. Lack of gastric contractile activity in vagotomised subjects sometimes delayed passage of the pill for several hours but, with $x$-ray screening and suitable positioning of the patient, correct placement of the pill was achieved in all.

Patients sat quietly in armchairs or reclined in bed against a bed-rest during the study periods, or slept, lying in bed. A standard $540 \mathrm{kCal}$ mixed meal $^{3}$ was given on the evening of the study.

No other food was allowed and only sips of water were taken. Recording of gut activity continued overnight until the next morning.

At the end of the study, the pill was removed by slow traction on the attached thread and recalibrated. The magnetic tapes on which the pressure changes were recorded were replayed to give an analogue record of continuous pressure activity throughout the study. Periods of regular contractile activity (phase III or the activity front of the motor complex) were identified on the replayed recordings (Figs 2-4). Cycle frequency during fasting was measured as the period between the onset of

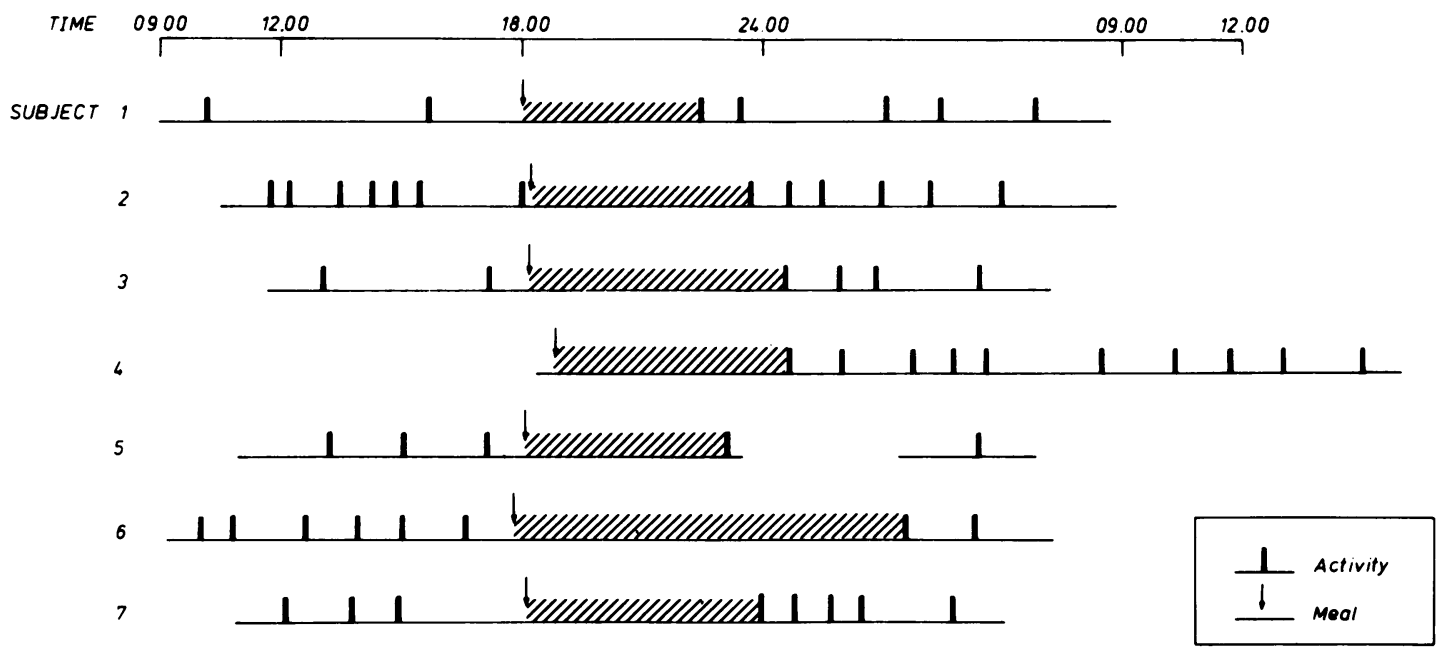

Fig. 2 Results of the seven studies performed on non-operated duodenal ulcer patients. Vertical bars represent phase III motor activity. The horizontal line indicates the duration of recording, and interruption of the baseline represents loss of radiosignal. Meals were taken at times shown by vertical arrows. Diagonal hatching indicates the interval between the meal and the first postprandial complex. 


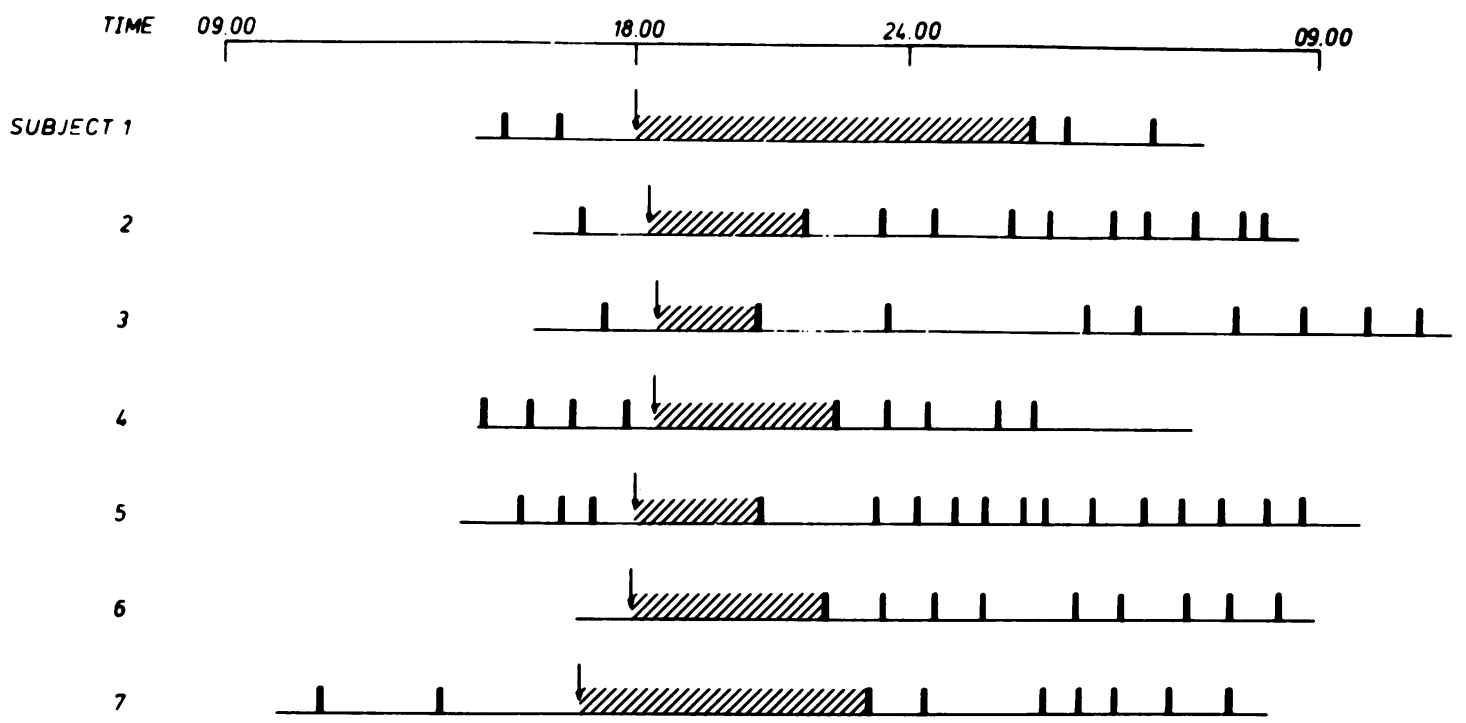

Fig. 3 Results of studies on asymptomatic post-vagotomy patients. Symbols as in Fig. 2.

successive phase III activity periods. Feeding activity was defined as the duration of inhibition of recognised fasting activity, measured as the interval between the onset of eating and the next observed period of regular contractile activity (phase III).

\section{Results}

\section{FASTING ACTIVITY}

The intervals between periods of regular contractile activity (phase III) were measured for all patients during sleep and waking. The data for duodenal ulcer patients and vagotomy patients were then compared (Table 3) using the median test. ${ }^{11}$ No significant difference was found. There was no significant difference between these data and those previously published by us $^{3}$ in a study of healthy volunteers.

FEEDING ACTIVITY

The duration of feeding activity for all subjects is shown in Table 4. Because the data in each group do not show a normal distribution, statistical analysis was performed using non-parametric ranking tests (Wilcoxon rank sum). The duration of feeding activity for the duodenal ulcer patient group was

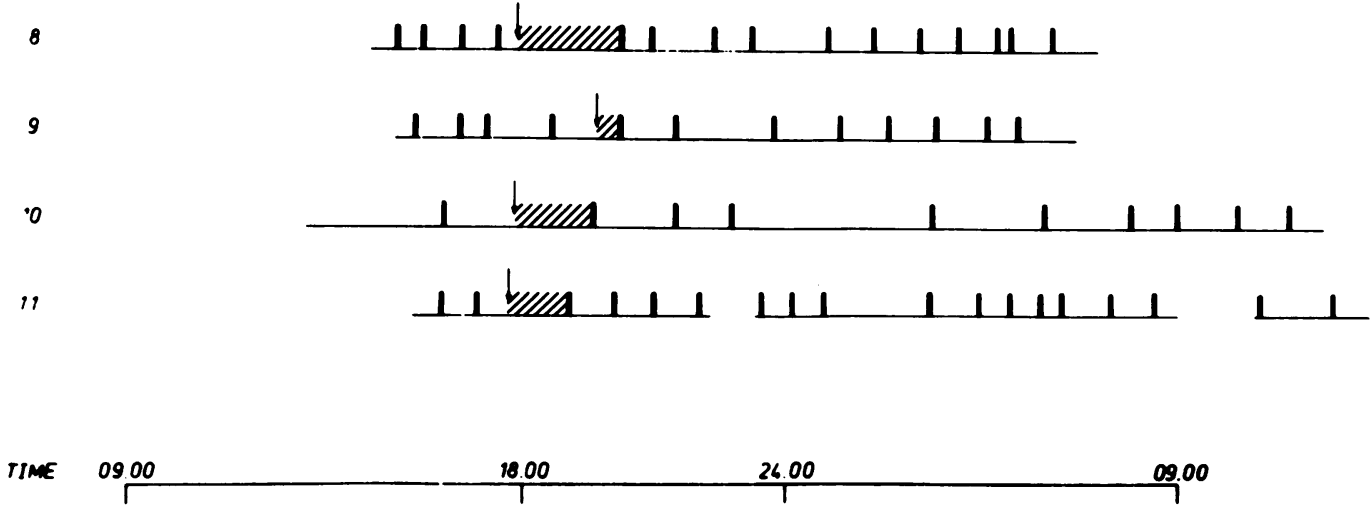

Fig. 4 Results of studies on four post-vagotomy subjects with chronic diarrhoea. Symbols as in Fig. 2. 
Table 3 Intervals between fasting activity fronts

\begin{tabular}{lll}
\hline & \multicolumn{2}{l}{ Median value (min) } \\
\cline { 2 - 3 } & DU patients & TV patients \\
\hline Awake & 70 & 65 \\
Sleeping & 75 & 65 \\
\hline
\end{tabular}

Comparison (median test) of: TV vs DU awake, $\mathrm{p}>0.05$; TV vs DU asleep, $p>0.05$; DU awake vs asleep, $p>0.05$.

found to be significantly longer than the vagotomy group without diarrhoea $(\mathrm{p}<0 \cdot 05)$. There was a further reduction in duration of feeding activity for truncal vagotomy patients with diarrhoea as compared with asymptomatic truncal vagotomy patients $(\mathrm{p}<0 \cdot 01)$.

Table 4 Duration of feeding activity

\begin{tabular}{|c|c|c|c|c|c|}
\hline \multicolumn{2}{|c|}{$D U$ patients } & \multicolumn{2}{|c|}{$\begin{array}{l}\text { TV patients } \\
\text { without } \\
\text { diarrhoea }\end{array}$} & \multicolumn{2}{|c|}{$\begin{array}{l}T V \text { patients } \\
\text { with diarrhoea }\end{array}$} \\
\hline Subject & $\begin{array}{l}\text { Duration } \\
\text { (min) }\end{array}$ & Subject & $\begin{array}{l}\text { Duration } \\
\text { (min) }\end{array}$ & Subject & $\begin{array}{l}\text { Duration } \\
\text { (min) }\end{array}$ \\
\hline 1 & 273 & 1 & 520 & 8 & 132 \\
\hline 2 & 339 & 2 & 211 & 9 & 50 \\
\hline 3 & 387 & 3 & 138 & 10 & 135 \\
\hline 4 & 325 & 4 & 240 & 11 & 134 \\
\hline 5 & 307 & 5 & 166 & & \\
\hline 6 & 587 & 6 & 262 & & \\
\hline \multirow[t]{2}{*}{7} & 356 & 7 & 284 & & \\
\hline & & $\mathrm{p}<0.05$ & & $\mathrm{p}<0.01$ & \\
\hline
\end{tabular}

DIURNAL VARIATION

During sleep, healthy adults show marked diminution of the duration of irregular contractile activity (phase II), whereas the duration of regular activity fronts (phase III) is unchanged. ${ }^{12}$ There was no difference in this respect between the findings in ulcer patients, both operated and non-operated, and those obtained in healthy volunteers in a previous study. ${ }^{12}$

\section{Discussion}

Our results show that an effect of truncal vagotomy combined with a drainage procedure upon the small intestinal feeding pattern is to reduce its duration; the lack of apparent differences in pattern between the various forms of drainage procedure suggests that the vagotomy is probably the major determinant of this reduction. Similar findings in dogs after truncal vagotomy have been described by other workers. ${ }^{4-6}$ Such effects could conceivably be produced by the several different mechanisms discussed below.
Impaired sensitivity of duodenal receptors (or, after gastroenterostomy, bypass of receptors) might result in reversion to a fasting motor pattern before the completion of gastric emptying. The premature migrating phase III pattern might then sweep underdigested food through the small intestine at a rate which exceeded its absorptive capacity and perhaps result in diarrhoea, depending upon the prematurity of the pattern and the quantity of food propelled into the colon. On this point, however, the evidence is equivocal. Wilbur and Kelly ${ }^{13}$ found continued osmoreceptor activity after vagotomy, and Shahidullah et al ${ }^{14}$ showed that, after surgery, gastric emptying of fluids was still retarded by instillation of nutrient into the duodenum. On the other hand, Hall and Read ${ }^{15}$ reported impaired osmoreceptor function, while Malagelada et $a l^{16}$ found an impaired exocrine pancreatic response to intraduodenal nutrients; in addition, the enterogastric inhibitory reflex is impaired by vagotomy. ${ }^{17}$

Altered gastric emptying might also account for our findings. An excessively rapid rate of gastric emptying might quickly reduce the gastric volume and the duodenal nutrient density below a level capable of inhibiting the fasting pattern and hence allow the premature phase III return. Conversely, gastric stasis could also conceivably allow the premature reversion of phase III pattern if the rate of delivery of nutrients into the small intestine was sufficiently slow. Abnormalities of gastric emptying of mixed meals after vagotomy have been reported $^{18-20}$ but the situation remains far from clear. After vagotomy, the variables affecting gastric emptying include the interval between vagotomy and its assessment, ${ }^{20}$ the nature of the meal (liquid meals empty faster than solid meals ${ }^{21}$ ), and the posture of the patient during study. ${ }^{22}$ Moreover, the apparent 'rate' of gastric emptying may depend upon the index used; after vagotomy, the time taken for the stomach to empty half its contents may be shorter, although complete emptying may be delayed. ${ }^{23}$ Nor can it be assumed that there is a consistent effect of vagotomy on gastric emptying; a study $^{24}$ using radio-labelled chicken liver incorporated into a standard meal showed that, after vagotomy with drainage, some patients had significantly faster rates than normal controls, while others were significantly slower. Whether one individual might exhibit both effects on different occasions is not known, but, in our study, one vagotomised subject demonstrated a duration of feeding activity which was double that shown by the rest of the group. According to the literature, the variation in gastric emptying between different types of meals and different individuals is so great that it would be unwise to make any assumptions about the emptying 
of the test meals in our study groups. Only simultaneous study of motility and gastric emptying (including emptying of aqueous, lipid, and solid phases) could resolve this question.

While it would be clearly unwise to speculate on changes in our asymptomatic operated patients other than those that we have demonstrated, our data on patients with diarrhoea are consistent with a previous report of rapid gastric emptying in similar patients. ${ }^{25}$ In these cases it seems possible that the premature return of fasting motor activity with migrating complexes is associated with the propulsion of digesta and bile acids ${ }^{10}$ beyond the terminal ileum before absorption is complete, with consequent catharsis in the colon. Our data provide no support for the hypothesis that altered small bowel motility occurs in non-operated duodenal ulcer patients without pyloric obstruction.

Finally, it could be argued that our single sensor cannot detect migration, and that our data may not present a true picture of the migrating complex. As shown in Fig. 1, even with a single sensor, the motor pattern produced by the passage of a migrating complex is unique, while recording from multiple sensors gives information over only 75 or $100 \mathrm{~cm}$ of proximal digestive tract. ${ }^{26} 27$ Although it seems some motor complexes arise distal to the stomach ${ }^{28}$ or duodenum, ${ }^{26}$ most motor complexes probably traverse at least the proximal small bowel. ${ }^{27}$ The extent to which complexes may die away, or fuse along the entire small bowel, and the incidence of ill-defined entities such as 'ectopic fronts' and 'mini-fronts'29 remains to be defined. Our method shows only pressure activity, presumed to be migratory, at a single site in the small bowel, but this information seems to be sufficient to detect pathophysiological changes in motility patterns.

We wish to thank $\mathrm{Mr}$ W Dobinson, Sister G Keenan, and Mrs A Ling for technical assistance, Stephen Evans MSc for expert statistical advice, and the Wellcome Trust and the Mason Medical Research Foundation for financial support.

\section{References}

1 Boldyreff W. Fonction periodique de l'organisme chez l'homme et les animaux d'ordre superieur. $Q J$ Exp Physiol 1916; 10: 175-201.

2 Itoh Z, Honda R, Aizawa I, et al. Interdigestive motor activity of the lower oesophageal sphincter in the conscious dog. Am J Dig Dis 1978; 23: 239-47.

3 Thompson DG, Wingate DL, Archer L, Benson MJ,
Green WJ, Hardy RJ. Normal patterns of human small bowel motor activity recorded by prolonged radiotelemetry. Gut 1980; 21: 500-6.

4 Marik F, Code CF. Control of the interdigestive myoelectric activity in dogs by the vagus nerves and pentagastrin. Gastroenterology 1975; 69: 387-95.

5 Weisbrodt NW, Copeland EM, Moore EP, Kearley RW, Johnson LR. Effect of vagotomy on electrical activity of the small intestine of the dog. Am J Physiol 1975; 228: 650-4.

6 Reverdin N, Hutton M, Ling A, Thompson HH, Wingate DL, Christofides N, Adrian TE, Bloom SR. Vagotomy and the motor response to feeding. In: Christensen J, ed. Gastrointestinal motility. New York: Raven Press, 1980: 359-63.

7 Glazebrook AJ. Functional disorders of small bowel after gastrectomy and vagotomy. Lancet 1952; 1: 895-9.

8 Roth HP, Beams AJ. The effect of vagotomy on the motility of the small intestine. Gastroenterology 1959; 36: 452-8.

9 Catchpole BN, Duthie HL. Postoperative gastrointestinal complexes. In: Duthie HL, ed. Gastrointestinal motility in health and disease. Lancaster: MTP Press, 1978: 33-41.

10 Allan JG, Gerskowitch VP, Russell RI. A study of the role of bile acids in the pathogenesis of post vagotomy diarrhoea. Gut 1973; 14: 423-4.

11 Siegel S. Nonparametric statistics for the behavioral sciences. Kogakusha: McGraw-Hill, 1956.

12 Ritchie HD, Thompson DG, Wingate DL. Diurnal variation in human jejunal fasting motor activity. $J$ Physiol 1980; 305: 54P.

13 Wilbur BG, Kelly KA. Effect of proximal gastric, complete gastric and truncal vagotomy on canine gastric electric activity motility and emptying. $A m J$ Surg 1973; 178: 295-303.

14 Shahidullah M, Kennedy TL, Parks TG. The vagus, the duodenal brake and gastric emptying. Gut 1975; 16: $331-6$.

15 Hall WH, Read RC. Effect of vagotomy on gastric emptying. Am J Dig Dis 1975; 15: 1047-53.

16 Malagelada JR, Go VL, Summerskill WHJ. Altered pancreatic and biliary function after vagotomy and pyloroplasty. Gastroenterology 1974; 66: 22-7.

17 Thomas JE, Baldwin MV. Pathways and mechanisms of regulation of gastric motility. In: Code CF, ed. Handbook of physiology, sect 6. Alimentary canal. Washington: American Physiological Society, 1968, Vol 96: 1937-68.

18 Harvey RF, Mackie DB, Brown NJG, Keeling DH, Davies WT. Measurement of gastric emptying time with a gamma camera. Lancet 1970; 1: 16-8.

19 Meek WJ, Herrin RC. The effect of vagotomy on gastric emptying time. Am J Physiol 1934; 109: 221-31.

20 Hewlett PJ, Sheiner HJ, Barber DC, Ward AS, Perez-Aquila CA, Duthie HL. Gastric emptying in control subjects and patients with duodenal ulcer before and after vagotomy. Gut 1976; 17: 542-50.

21 Millar JW, McLoughlin GP, Macleod IB, Heading RC. The effect of vagotomy on gastric emptying of solid and liquid components of a meal. In: Duthie HL, ed. 
Gastrointestinal motility in health and disease. Lancaster: MTP Press, 1978: 215-22.

22 Hancock BD, Bowen-Jones E, Dixon R, Festa T, Dymock IW, Cowley DJ. The effect of posture on the gastric emptying of solid meals in normal subjects and patients after vagotomy. Br J Surg 1974; 61: 945-9.

23 Clark RJ, Alexander-Williams J. The effect of preserving antral innervation and of a pyloroplasty on gastric emptying after vagotomy in man. Gut 1973; 14: 300-7.

24 MacGregor IL, Martin MS, Meyer JH. Gastric emptying of solid food in normal man and after subtotal gastrectomy and truncal vagotomy with pyloroplasty. Gastroenterology 1977; 72: 206-11.

25 Colmer MR, Owen GM, Shields R. Pattern of gastric emptying after vagotomy and pyloroplasty. $\mathrm{Br} \mathrm{Med} \mathrm{J}$ 1973; 2: 448-50.

26 Vantrappen G, Janssens J, Hellemans J, Ghoos Y. The interdigestive motor complex of normal subjects and patients with bacterial overgrowth of the small intestine. J Clin Invest 1977; 59: 1158-66.

27 Fleckenstein P, Krogh F, Oigaard A. The interdigestive myoelectrical complex and other migrating electrical phenomena in the human small intestine. In: Duthie HL, ed. Gastrointestinal motility in health and disease. Lancaster: MTP Press, 1978: 19-27.

28 Finch F, Ingram D, Henstridge J, Catchpole B. The relationship of sleep stage to the migrating gastrointestinal complex in man. In: Christensen J, ed. Gastrointestinal motility. New York: Raven Press, 1980: 261-5.

29 Wingate DL, Ruppin H, Green WER, Thompson $\mathrm{HH}$, Domschke W, Wunsch E, Demling L, Ritchie HD. Motilin-induced electrical activity in the canine gastrointestinal tract. Scand J Gastroenterol 1976; suppl (11), 39: 111-8. 